\title{
Relation of Indoor Storage of Dried Tobacco Leaves to Reporting of Respiratory Symptoms: Case of Tobacco Farms Households in South Lebanon
}

\section{Bazzi A ${ }^{1}$, Zaatari $\mathbf{G}^{1}$, Makki $\mathbf{M}^{2}$, Tamim $\mathbf{H}^{2,3}$ and Zein-El-Dine $\mathbf{S}^{3^{*}}$}

${ }^{1}$ Department of Pathology and Laboratory Medicine, Environmental Core Laboratory, American University of Beirut Medical Center, Beirut, Lebanon ${ }^{2}$ Clinical Research Institute, American University of Beirut Medical Center, Beirut, Lebanon

${ }^{3}$ Department of Internal Medicine, Faculty of Medicine, American University of Beirut Medical Center, Beirut, Lebanon

\begin{abstract}
Objective: Earlier studies associated the chronic exposure to the dust of tobacco leaves with increased occurrence of allergies, skin rashes, rhinitis, nausea, dizziness, vomiting, and various respiratory disorders in tobacco farmers and processors. We aimed to investigate if oriental tobacco farm households who store dried tobacco leaves inside their house are more likely to experience and report respiratory and allergic episodes or illnesses than households storing dried tobacco leaves outside the house.

Methods: A cross-sectional study was conducted among tobacco farm households within the Caza of Bint Jbeil in South Lebanon. Demographic, socioeconomic, household characteristics and respiratory symptoms were assessed by separate sets of questions. The questionnaire assessed respiratory symptoms, allergies' and smoking habits using questions items adopted mainly from The European Community Respiratory Health Survey II.

Results: A borderline association was found between storage status of tobacco leaves and respiratory symptoms $(\mathrm{OR}=1.68(95 \% \mathrm{Cl}=0.93-3.03, \mathrm{p}=0.09)$. Overall, $37.0 \%$ among those who stored tobacco leaves inside their house reported respiratory symptoms in comparison to $26.0 \%$ among those who stored tobacco leaves outside.

Conclusions: The study findings suggest that indoor storage of dried tobacco leaves can slightly contribute to aggravation of respiratory symptoms. Prospective cohort studies in tobacco farming communities would be useful in determining if indoor storage of dried tobacco leaves can lead to development of asthma and aggravation of symptoms especially among younger age group.
\end{abstract}

Keywords: Indoor storage; Dried tobacco; Respiratory symptoms; Lebanon

\section{Introduction}

Earlier studies among tobacco workers and processers has associated the exposure to tobacco dust with different respiratory disorders such as occupational asthma [1], increased occurrence of chronic respiratory symptoms [1,2] including chronic cough, phlegm, dyspnea, chest tightness, snuffle, snivel and allergic rhinitis [2]; wheezing, attacks of shortness of breath with wheezing, dyspnoea, and rhinitis [3]; chest tightness and wheezing [4]; mild obstructive ventilation disturbances [5] and decreased lung function tests [1,2,6,7], allergic alveolitis [8] and chronic bronchitis [9]. Earlier studies have also associated the exposure to tobacco dust with acute episodes of nose and throat dryness as well as eye irritation during work shifts [1], skin allergies [2,10], as well as vomiting, dizziness, and headache [11]. Risk from tobacco dust is believed to affect all people involved in tobacco production or live near tobacco-growing fields including processors, farmers, children, pregnant women and older people $[12,13]$. Studies targeting oriental tobacco farm households mainly investigated the economic impact of oriental tobacco leave production in Turkey and Lebanon, but not health effects $[14,15]$.

This study is the first to address the oriental tobacco farmers' house as a work place that puts home attendees at increased risk for chronic respiratory diseases and allergies. Specifically, it intends to investigate the hypothesis that occupants of households who store dried tobacco leaves inside the house are more likely to experience and report respiratory and allergic episodes or illnesses than households storing dried tobacco leaves outside the house.

\section{Methods}

\section{Study design}

The study conducted a cross-sectional descriptive design of 258 representative tobacco farming households.

\section{Setting and study population}

Participating households represent $5.6 \%$ of active farmers located mainly within the Caza of Bint Jbeil, South Lebanon. Tobacco farm households were distributed in the villages and towns of Rmaish (33.3\%, $\mathrm{n}=86$ ), Ramia (19.8\%, $\mathrm{n}=51)$, Debel (15.9\%, $\mathrm{n}=412)$, Dehayre $(13.2 \%, \mathrm{n}=34)$, Marwahin $(7 \%, \mathrm{n}=18)$, Yarin $(6.2 \%, \mathrm{n}=16)$, Kouzah $(2.7 \%, \mathrm{n}=7)$ and Al-Bistan $(1.9 \%, \mathrm{n}=5)$.

\section{Inclusion/exclusion criteria}

Inclusion criteria for this study included currently active households in tobacco farming with multiple family members and only those who

*Corresponding author: Salah Zein-El-Dine, Department of Internal Medicine Faculty of Medicine, American University of Beirut Medical Center, Beirut, Lebanon, Tel: +961-1-350000 Ext: 4526; E-mail: sz01@aub.edu.lb

Received October 05, 2018; Accepted November 09, 2018; Published Novembe 15, 2018

Citation: Bazzi A, Zaatari G, Makki M, Tamim H, Zein-El-Dine S (2018) Relation of Indoor Storage of Dried Tobacco Leaves to Reporting of Respiratory Symptoms: Case of Tobacco Farms Households in South Lebanon. J Pulm Respir Med 8: 478 doi: 10.4172/2161-105X.1000478

Copyright: $\odot 2018$ Bazzi A, et al. This is an open-access article distributed under the terms of the Creative Commons Attribution License, which permits unrestricted use, distribution, and reproduction in any medium, provided the original author and source are credited. 
store tobacco leaves whether inside or outside the house premises. Excluded from this study were retired tobacco farmers, as well as those who didn't consent to the study.

\section{Farming process}

Oriental tobacco farming process involves a seedling stage where tobacco seeds are implanted within a small plot/garden in front or behind the house where it is sprayed heavily with herbicides, fungicides or other pesticides. Mature seedlings with strong roots are then transferred to tobacco plots field, where it grows further and green leaves are individually harvested on a daily basis. In terms of duration, the seedling cycle averages 60 days and starts as early as October and lasts as late as April, whereas the tobacco leaves cycle averages 60 days and starts as early as May and lasts until late September. Harvested green leaves are organized in special threads based on their size and maturity. The threaded leaves are held on wooden holders (El Mancher) under sun until the leaves become light brown in color and protected from morning dew with nylon covers during the night [16]. Dried tobacco leaves are then stored indoors for an average of 4.4 months until it is shipped to Regie Libanaise des Tabacs et Tombacs. Prior to shipment, the flattened leaves (referred to as Mobsat) are gathered in circular consecutive layers (referred to as El Tadnik) with the leave heads placed to the inside and neck to the outside until their moisture is fully evaporated (without losing their color or features). Dried flattened leaves are packaged in boxes and then shipped to Regie Libanaise des Tabacs et Tombacs.

After the yellow color of the leaves is fixed, the threaded leaves are held on wooden holders in the assigned drying (El Mancher) so that the leaves become light brown in color under appropriate moisture (65$70 \%)$ and temperature $\left(16-32^{\circ} \mathrm{C}\right)$ and protected from morning dew with nylon covers during the night [16]. After the drying stage, the flattened leaves (referred to as Mobsat) are gathered in circular consecutive layers (referred to as El Tadnik) with the leave heads placed to the inside and neck to the outside until their moisture is fully evaporated (without losing their color or features). Dried tobacco leaves are then stored until packaged in wooden boxes so that the head of the leaves is directed to the inside and then shipped to Regie Libanaise des Tabacs et Tombacs [16]. In terms of duration, the seedling cycle averages 60 days and starts as early as October and lasts as late as April, whereas the tobacco leaves cycle averages 60 days and starts as early as May and lasts until late September.

\section{Outcomes}

Outcome variables included the storage location of dried tobacco leaves (inside house/outside), respondent history of breathing difficulties, any change in respiratory health status over the past year, history of asthma or other respiratory disease by respondent or any other family member in the household. Information about respiratory symptoms included two items for wheezing, five items for shortness of breath, one item for coughing and one item for phlegm. The frequency of experiencing each respiratory symptom was assessed along with the change in severity of reported symptoms. The history of respiratory, nasal and skin allergies was also investigated among those specified family members with chronic respiratory diseases.

\section{Data collection}

Data was collected using structured interviews. Follow-up phone interviews with representative participants were done to verify and confirm some of the study findings. Tobacco farm households were visited during August to October, 2013. Household interviews were carried out by an experienced field surveyor knowledgeable of the area under study. All interviews were carried out in the presence of female and male heads of the households and other representative family members. The interview ranged from 45 minutes up to 1.5 hour per household depending on family size, the complexity of the health profile of each individual in the household, participant's interest level, conversational style, and the number of interruptions.

A structured questionnaire was specifically designed from multiple preexisting questionnaires to fit the purpose of the study [17-21]. Information was collected about socio-demographic information of overall family member household, tobacco farming history, proximity of farming plots to house premises, storage location of dried tobacco leaves (indoors/outdoors), storage period of dried tobacco leaves, whether the dried tobacco leaves storage room is also used as sleeping room by any family member, storage room and overall house size in meter square, indoor air cooling and heating methods, presence of windows in the storage room, frequency and time windows are opened, household cleanliness and adopted on farm safety practices and wearing of personal protective equipment. The experienced respiratory symptoms and allergies' along with medications, and smoking patterns of family members, were assessed using The European Community Respiratory Health Survey II abbreviated as ECRHS II [21]. A separate questionnaire form was filled for each person in visited household (respondent and any other family member) with asthma or other physician diagnosed respiratory disease. The questions were modified to elicit, as much as possible, information about respiratory symptoms and allergies during the previous 12 months of the subject's life. The modifications from the pre-existing scales were mainly in the response options. As applicable to the type of questions, a two, three, four and five response scale was used. For example, history of breathing difficulties was assessed using binary response. If positive, its frequency was assessed using 3 response scale (only rarely, repeatedly but it always get completely better, continuously so that the breathing is never quite right). The change in respiratory health status over the past year was assessed using 3 response scale (usual, better than usual and worse than usual). Information assessed about asthma or chronic respiratory symptoms included two items for wheezing (wheezing / whistling without having a cold; unable to breath when the wheezing noise was present), five items for shortness of breath (upon waking in the morning; while at rest anytime; when hurrying on level ground or walking up a slight hill; following strenuous activity at any time; when walking at own pace with other people of similar age on level ground; and, had to stop to breath), one item for coughing (waking up by cough attack), one item for chest constriction (upon wake up), and one item for phlegm (bring up any phlegm from the chest in the morning, during the day or at night in the winter).

The frequency of each respiratory symptom, was assessed using 5 response scale ( 0 -none, 1-less than one incident /month, 2-one incident /month, 3-two incidents /month, and 3-more than 2 incidents /month). Change in severity of reported respiratory symptoms was assessed over the past 6 month period to account for the overlap in farming phases among visited tobacco farm households using 4 response scale (0did not occur , 1-no change, 2-decrease, 3-increase). The history of respiratory, nasal and skin allergies was also investigated among those specified family members with chronic respiratory diseases using 3 response scale (No, Yes, Don't know). Respiratory allergies (reflected in coughing, wheezing and shortness of breath) were assessed using 9 items (whenever they have a cold or respiratory infection; upon change in weather; occurring when usually not sick; occurring during playing or running; occurring after playing or running; when working around in a room where dried tobacco leaves are present; when working around 
wood smoke; while present in a room where carpets are being dusted or vacuumed; when around furry animals or birds).

The Institutional Review Board at the American University of Beirut reviewed and approved this study.

\section{Statistical analysis}

Statistical Package for the Social Sciences (SPSS) version 23 was used for data entry and analysis. Descriptive analyses were carried out by calculating the number and percent for categorical variables, whereas the mean and standard deviation $( \pm S D)$ were calculated for the continuous variables. The bivariate analyses were performed using Chisquare test, fisher's exact test or independent sample t-test to assess the association between demographic, socioeconomic, household, smoking factors and the storage status of dried tobacco leaves as appropriate. Moreover, non-parametric Mann-Whitney test was used to assess the association between experienced respiratory symptoms and the storage status of dried tobacco leaves. Hierarchical binary logistic regression analysis using a forward selection procedure was conducted to examine the relationship between the reported respiratory symptoms and various potential predictors while imposing the storage status of dried tobacco leaves as main exposure. All determinants that are statistically and clinically significant were entered into the regression analysis. Statistical significance was defined at the 0.05 level.

\section{Results}

In total, 258 tobacco farmers were included in the study. Overall, 77 of them (29.8\%) stored the dried tobacco leaves outside their house and $181(70.2 \%)$ inside their house. Table 1 summarizes the demographic, socioeconomic and household factors among the study sample and their association with the storage status of tobacco leaves. Moreover, $67.4 \%$ of the farmers were aged above 40 years and $51.2 \%$ were males. As for educational level, most has elementary and above level (49.0\%); illiterate participants represented $19.8 \%$ of the sample. Less than one third (30.6\%) of the participants had 26 to 50 years of experience in tobacco farming. Most participants were from large families counting between 6 and 12 members (44.2\%) and the majority (94.6\%) had an income above USD 30,000 per year. Around $38.4 \%$ of the farmers lived in a house with an area of less than $150 \mathrm{~m}^{2}$. Close to two thirds (63.7\%) cultivated tobacco leaves in an outside area of less than 0.6 hectares. Overall, $39.8 \%$ of them produced less than $500 \mathrm{~kg}$ of tobacco leaves per year while $21.5 \%$ produced above $1,000 \mathrm{~kg}$ per year. Moreover, $62.7 \%$ of the farmers used the charcoal and wood method to heat their indoor during winter time and $46.7 \%$ didn't have any air conditioning method to cool and ventilate their houses during summer time. While $70.4 \%$ of the farmers implanted their tobacco leaves seeds in seedling plots, only $12.6 \%$ purchased the seedlings to replant it into tobacco fields. The average storage period of tobacco leaves is 4.4 months (SD 0.9). Finally, it was observed that $70.9 \%$ of the farmers are smokers. Comparison of these factors between farmers that stored the tobacco leaves inside or outside their house showed significant differences only in family size $(\mathrm{P}=0.05)$, and heating method $(\mathrm{P}=0.03)$. Large families (6-12 members) are less likely to store the tobacco leaves outside in comparison to the small families (1-5 members) (35.1\% versus $64.9 \%$, respectively) Additionally, farmers that used charcoal and wood heating method reports using more the inside house storage (67.0\%) in comparison to farmers that uses other heating method (33.0\%). Other factors did not show any statistically significant difference between the two groups of farmers.

The prevalence of self-reported respiratory symptoms at the level of total family members of surveyed tobacco farm households were (data not shown): 3\% "wheezing", 3\% "breathlessness with wheezing", $2 \%$ "shortness of breath upon waking in the morning", $2 \%$ "shortness of breath when hurrying on level ground or walking up a slight hill", $2 \%$ "shortness of breath following strenuous activity", $1 \%$ "shortness

\begin{tabular}{|c|c|c|c|c|c|c|}
\hline & & & & \multicolumn{2}{|c|}{ Storage status of tobacco leaves } & \multirow[b]{2}{*}{$P$ value } \\
\hline \multicolumn{3}{|c|}{ Total sample } & \multirow{2}{*}{$\begin{array}{c}\text { All } \\
\mathrm{n}=\mathbf{2 5 8}\end{array}$} & $\begin{array}{c}\begin{array}{c}\text { Outside house n } \\
\text { (\%) }\end{array} \\
n=77(29.8 \%)\end{array}$ & $\begin{array}{c}\begin{array}{c}\text { Inside house } \\
n(\%)\end{array} \\
n=181(70.2 \%)\end{array}$ & \\
\hline \multirow{7}{*}{ Demographic } & \multirow[b]{2}{*}{ Gender } & Male & & $37(48.1 \%)$ & 95 (52.5\%) & \multirow[b]{2}{*}{0.51} \\
\hline & & Female & $126(48.8 \%)$ & $40(51.9 \%)$ & $86(47.5 \%)$ & \\
\hline & \multirow{2}{*}{ Age } & $\leq 40$ years & $84(32.6 \%)$ & $25(32.5 \%)$ & $86(47.5 \%)$ & \multirow{2}{*}{0.98} \\
\hline & & $>40$ years & $174(67.4 \%)$ & $52(67.5 \%)$ & $122(67.4 \%)$ & \\
\hline & \multirow{3}{*}{ Education } & Illiterate & $51(19.8 \%)$ & $11(14.5 \%)$ & $40(22.1 \%)$ & \multirow{3}{*}{0.26} \\
\hline & & $\begin{array}{c}<5 \text { years of basic } \\
\text { education }\end{array}$ & $80(31.1 \%)$ & $28(36.8 \%)$ & $52(28.7 \%)$ & \\
\hline & & Elementary and up & $126(49.0 \%)$ & $89(49.2 \%)$ & $89(49.2 \%)$ & \\
\hline \multirow{7}{*}{ Socioeconomic } & \multirow{3}{*}{ Experience in tobacco farming (years) } & $1-15$ & $103(39.9 \%)$ & $36(46.8 \%)$ & $67(37.0 \%)$ & \multirow{3}{*}{0.33} \\
\hline & & $16-25$ & $76(29.5 \%)$ & $21(27.3 \%)$ & $55(30.4 \%)$ & \\
\hline & & $26-50$ & $79(30.6 \%)$ & $20(26.0 \%)$ & $59(32.6 \%)$ & \\
\hline & \multirow{2}{*}{ Family size (members) } & $1-5$ & $144(55.8 \%)$ & $50(64.9 \%)$ & $94(51.9 \%)$ & \multirow[b]{2}{*}{0.05} \\
\hline & & $6-12$ & $114(44.2 \%)$ & $27(35.1 \%)$ & $87(48.1 \%)$ & \\
\hline & \multirow[b]{2}{*}{ Annual family income } & $\leq 30,000$ USD & $14(5.4 \%)$ & $5(6.5 \%)$ & $9(5.0 \%)$ & \multirow[b]{2}{*}{0.76} \\
\hline & & $>30,000$ USD & $244(94.6 \%)$ & $72(93.5 \%)$ & $172(95.0 \%)$ & \\
\hline
\end{tabular}




\begin{tabular}{|c|c|c|c|c|c|c|}
\hline \multirow{17}{*}{ Household } & \multirow{3}{*}{ House size } & $\leq 150 \mathrm{~m}^{2}$ & $96(38.4 \%)$ & $31(43.1 \%)$ & $65(36.5 \%)$ & \multirow{3}{*}{0.42} \\
\hline & & $151-200 \mathrm{~m}^{2}$ & $92(36.8 \%)$ & $27(37.5 \%)$ & $65(36.5 \%)$ & \\
\hline & & $>200 \mathrm{~m}^{2}$ & $62(24.8 \%)$ & $14(19.4 \%)$ & $48(27.0 \%)$ & \\
\hline & \multirow{2}{*}{$\begin{array}{l}\text { Area in hectare cultivated with } \\
\text { tobacco }\end{array}$} & $\leq 0.6$ & $163(63.7 \%)$ & $54(71.1 \%)$ & $109(60.6 \%)$ & \multirow[b]{2}{*}{0.11} \\
\hline & & $>0.6$ & $93(36.3 \%)$ & $22(28.9 \%)$ & $54(71.1 \%)$ & \\
\hline & \multirow{3}{*}{ Output of tobacco leaves/year $(\mathrm{kg})$} & $1-500$ & $102(39.8 \%)$ & $35(46.1 \%)$ & $67(37.2 \%)$ & \\
\hline & & $501-1000$ & $99(38.7 \%)$ & $28(36.8 \%)$ & $71(39.4 \%)$ & 0.35 \\
\hline & & $>1000$ & $55(21.5 \%)$ & $13(17.1 \%)$ & $42(23.3 \%)$ & \\
\hline & \multirow{2}{*}{ Indoor heating } & $\begin{array}{c}\text { Charcoal and wood } \\
\text { heating }\end{array}$ & $160(62.7 \%)$ & $36(47.4 \%)$ & $120(67.0 \%)$ & \multirow{2}{*}{0.03} \\
\hline & & Fuel heater & $95(37.3 \%)$ & $36(47.4 \%)$ & $59(33.0 \%)$ & \\
\hline & \multirow[b]{2}{*}{ Indoor air conditioning } & No & $120(46.7 \%)$ & $31(40.8 \%)$ & $89(49.2 \%)$ & \multirow[b]{2}{*}{0.22} \\
\hline & & Yes & $137(53.3 \%)$ & $45(59.2 \%)$ & $92(50.8 \%)$ & \\
\hline & \multirow{2}{*}{ Proximity of seedling plots to house } & $\begin{array}{l}\text { Within garden in front/ } \\
\text { behind house }\end{array}$ & $178(70.4 \%)$ & $53(72.6 \%)$ & $125(69.4 \%)$ & \multirow{2}{*}{0.62} \\
\hline & & Others & $75(29.6 \%)$ & $20(27.4 \%)$ & $55(30.6 \%)$ & \\
\hline & \multirow{2}{*}{ Proximity of tobacco field to house } & $\begin{array}{l}\text { Within garden in front/ } \\
\text { behind house }\end{array}$ & $32(12.6 \%)$ & $7(9.5 \%)$ & $25(14.0 \%)$ & \multirow{2}{*}{0.33} \\
\hline & & Others & $221(87.4 \%)$ & $67(90.5 \%)$ & $154(86.0 \%)$ & \\
\hline & Storage period (months) & Mean $( \pm S D)$ & $4.4( \pm 0.9)$ & $4.5( \pm 0.7)$ & $4.3( \pm 0.9)$ & 0.16 \\
\hline \multirow[b]{2}{*}{ Smoking } & & No smoker & $75(29.1 \%)$ & $23(29.9 \%)$ & $52(28.7 \%)$ & \multirow[b]{2}{*}{0.85} \\
\hline & & Smokers & $183(70.9 \%)$ & $54(70.1 \%)$ & $129(71.3 \%)$ & \\
\hline
\end{tabular}

Table 1: Association between storage of dried tobacco leaves and demographic, socioeconomic, household factors.

of breath while walking at own pace with other people of similar age on level ground, and had to stop to breath", 3\%"ever waken-up by attack of cough", 3\%"ever waken up with feeling of tightness in chest at any time", $2 \%$ " bring up any phlegm from the chest first thing in the morning, during the day, or at night, in the winter". None reported "shortness of breath while at rest at any time. Whereas, the prevalence of self-reported nasal allergies is $1.2 \%$ and skin allergies is $0.28 \%$ at the level of total family members of surveyed tobacco farm households.

Table 2 illustrates the reported respiratory symptoms of the family members of tobacco farmers and their association with the storage status of tobacco leaves. It was observed that $66.3 \%$ of the sample did not report any respiratory disease or symptom while only $5.0 \%$ reported asthma, $16.7 \%$ reported respiratory problems other than asthma, and $12.0 \%$ reported some symptoms of allergy. A borderline significant trend $(\mathrm{P}=0.09)$ was noted between reported respiratory disease and storage of dried tobacco leaves. Among family members of farmers who stored the tobacco leaves outside house, $74.0 \%$ did not show any respiratory disease while $26.0 \%$ reported some respiratory problems. On the other hand, $37.0 \%$ of the farmers who reported some respiratory diseases were storing tobacco leaves inside their house in comparison to $63.0 \%$ that did not show any respiratory symptoms. The affected members were mostly the spouses $(42.5 \%)$ followed by the children or parents and siblings (35.0\%). The mean age of the affected members was 37.2 years (SD 19.5). Among family members of tobacco farmers that are using the inside house storage method, $61.9 \%$ reported some wheezing or whistling without having a cold, difficulty in breathing when the wheezing noise was present and waking up with a feeling of tightness in the chest in comparison to $38.1 \%$ that did not report these symptoms. Around $54.8 \%$ described production of phlegm during winter time in comparison to $45.2 \%$ that did not report this specific symptom. Farmers and their family members who used the outside storage are less likely to develop shortness of breath during morning walk (46.2\% versus $53.8 \%$, respectively), shortness of breath while at rest ( $15.4 \%$ versus $84.6 \%$, respectively) and a shortness of breath while hurrying (46.2\% versus. $53.8 \%$, respectively). None of the respiratory symptoms showed any statistically significant difference between the two groups of farmers that are using different storage methods.

Hierarchical binary logistic regression in Table 3 estimates the effect of inside tobacco leaves storage on farmers and their family members' respiratory diseases. After controlling for relevant factors, it was shown that family members of farmers that are exposed to inside house storage of tobacco leaves $(\mathrm{OR}=1.68, \mathrm{p}=0.09)$ were more likely to report respiratory symptoms compared to those who stored tobacco leaves outside their house.

\section{Discussion}

The percentage of the reported respiratory symptoms within the surveyed tobacco farm households are lower than the findings reported in previous studies in Lebanon with the exception of selfreported asthma. For example, Waked et al. estimated the prevalence of respiratory systems at the different Governate levels in Lebanon [22]. Since the surveyed villages and towns in this pilot study administratively fall under Governate of Nabatieh, the findings of this pilot study are compared to values reported by Waked \& Salameh [22] at the same Governate level. The $5 \%$ self-reported asthma in our study is higher than the $3.9 \%$ physician diagnosed asthma (PDA) reported by Waked and Salameh at Nabatieh Governate level [22]. They also reported a percentage of $12.7 \%$ "ever wheezing symptoms", $10.5 \%$ wheezing for 12 months", 5.7\%"wheezing on exercise", $15.4 \%$ "night cough", 10.5\%" productive cough for 12 months", and 3.5\% "chronic productive cough" at same studied Governative [22]. The percentage 
Citation: Bazzi A, Zaatari G, Makki M, Tamim H, Zein-El-Dine S (2018) Relation of Indoor Storage of Dried Tobacco Leaves to Reporting of Respiratory Symptoms: Case of Tobacco Farms Households in South Lebanon. J Pulm Respir Med 8: 478. doi: 10.4172/2161-105X.1000478

Page 5 of 7

\begin{tabular}{|c|c|c|c|c|c|c|}
\hline \multirow[b]{3}{*}{ Total sample } & & & \multirow{3}{*}{$\begin{array}{c}\text { All } \\
n=258\end{array}$} & \multicolumn{2}{|c|}{ Storage status of dried tobacco leaves } & \multirow{3}{*}{$P$ value } \\
\hline & & & & Outside house $\mathrm{n}(\%)$ & Inside house $\mathrm{n}(\%)$ & \\
\hline & & & & $\mathrm{n}=77$ & $n=181$ & \\
\hline \multirow{6}{*}{$\begin{array}{l}\text { Lifestyle } \\
\text { Respiratory } \\
\text { diseases }\end{array}$} & \multirow{4}{*}{ Asthma or respiratory disease } & No & $171(66.3 \%)$ & $57(74.0 \%)$ & $114(63.0 \%)$ & \multirow{4}{*}{0.35} \\
\hline & & Asthma only & $13(5.0 \%)$ & $4(5.2 \%)$ & $9(5.0 \%)$ & \\
\hline & & Respiratory problems other than asthma & $43(16.7 \%)$ & $10(13.0 \%)$ & $33(18.2 \%)$ & \\
\hline & & Allergy only & $31(12.0 \%)$ & $6(7.8 \%)$ & $25(13.8 \%)$ & \\
\hline & \multirow[b]{2}{*}{ Any respiratory disease } & No & $171(66.3 \%)$ & $57(74.0 \%)$ & $114(63.0 \%)$ & \multirow[b]{2}{*}{0.09} \\
\hline & & Yes & $87(33.7 \%)$ & $20(26.0 \%)$ & $67(37.0 \%)$ & \\
\hline & & & $\mathrm{N}=87$ & $\mathrm{~N}=\mathbf{2 0}$ & $\mathrm{N}=67$ & \\
\hline \multirow{4}{*}{$\begin{array}{l}\text { Demographic } \\
\text { variables }\end{array}$} & \multirow{3}{*}{ Affected members } & Respondent & $18(22.5 \%)$ & $5(26.3 \%)$ & $13(21.3 \%)$ & \multirow{3}{*}{0.12} \\
\hline & & Spouse & $34(42.5 \%)$ & $11(57.9 \%)$ & $23(37.7 \%)$ & \\
\hline & & Child/sibling/parents & $28(35.0 \%)$ & $3(15.8 \%)$ & $25(41.0 \%)$ & \\
\hline & Age & Mean ( $\pm S D)$ & $37.2( \pm 19.5)$ & $40.1( \pm 14.7)$ & $36.3( \pm 20.8)$ & 0.75 \\
\hline \multirow{20}{*}{$\begin{array}{l}\text { Experienced } \\
\text { respiratory } \\
\text { symptoms }\end{array}$} & \multirow{2}{*}{$\begin{array}{l}\text { Wheezing or whistling without } \\
\text { having a cold }\end{array}$} & No & $19(34.5 \%)$ & $3(23.1 \%)$ & $16(38.1 \%)$ & \multirow[b]{2}{*}{0.51} \\
\hline & & Yes & $36(65.5 \%)$ & $10(76.9 \%)$ & $26(61.9 \%)$ & \\
\hline & \multirow{2}{*}{$\begin{array}{l}\text { Unable to breath when the } \\
\text { wheezing noise was present }\end{array}$} & No & $20(36.4 \%)$ & $4(30.8 \%)$ & $16(38.1 \%)$ & \multirow[b]{2}{*}{0.75} \\
\hline & & Yes & $35(63.6 \%)$ & $9(69.2 \%)$ & $26(61.9 \%)$ & \\
\hline & \multirow{2}{*}{$\begin{array}{l}\text { Shortness of breath upon } \\
\text { waking in the morning }\end{array}$} & No & $31(56.4 \%)$ & $7(53.8 \%)$ & $24(57.1 \%)$ & \multirow[b]{2}{*}{1} \\
\hline & & Yes & $24(43.6 \%)$ & $6(46.2 \%)$ & $18(42.9 \%)$ & \\
\hline & \multirow{2}{*}{$\begin{array}{c}\text { Shortness of breath while at rest } \\
\text { anytime }\end{array}$} & No & $52(94.5 \%)$ & $11(84.6 \%)$ & $41(97.6 \%)$ & \multirow[b]{2}{*}{0.14} \\
\hline & & Yes & $52(94.5 \%)$ & $2(15.4 \%)$ & $1(2.4 \%)$ & \\
\hline & \multirow{2}{*}{$\begin{array}{l}\text { Shortness of breath when } \\
\text { hurrying on level ground or } \\
\text { walking up a slight hill }\end{array}$} & No & $32(58.2 \%)$ & $7(53.8 \%)$ & $23(41.8 \%)$ & \multirow{2}{*}{0.76} \\
\hline & & Yes & $23(41.8 \%)$ & $6(46.2 \%)$ & $17(40.5 \%)$ & \\
\hline & \multirow{2}{*}{$\begin{array}{l}\text { Shortness of breath following } \\
\text { strenuous activity at anytime }\end{array}$} & No & $28(50.9 \%)$ & $5(38.5 \%)$ & $23(54.8 \%)$ & 0.36 \\
\hline & & Yes & $27(49.1 \%)$ & $8(61.5 \%)$ & $19(45.2 \%)$ & \\
\hline & \multirow{2}{*}{$\begin{array}{l}\text { Shortness of breath when } \\
\text { walking at own pace with other } \\
\text { people of similar age on level } \\
\text { ground; and, had to stop to } \\
\text { breath }\end{array}$} & No & $36(66.7 \%)$ & $7(53.8 \%)$ & $29(70.7 \%)$ & \multirow[b]{2}{*}{0.34} \\
\hline & & Yes & $19(34.5 \%)$ & $6(46.2 \%)$ & $13(31.0 \%)$ & \\
\hline & \multirow{2}{*}{ Waking up by coughing attack } & No & $14(25.5 \%)$ & $5(38.5 \%)$ & $9(21.4 \%)$ & \multirow{2}{*}{0.28} \\
\hline & & Yes & $41(74.5 \%)$ & $8(61.5 \%)$ & $33(78.6 \%)$ & \\
\hline & \multirow{2}{*}{$\begin{array}{l}\text { Waking up with a feeling of } \\
\text { tightness in the chest }\end{array}$} & No & $20(36.4 \%)$ & $4(30.8 \%)$ & $16(38.1 \%)$ & 075 \\
\hline & & Yes & $35(63.6 \%)$ & $9(69.2 \%)$ & $26(61.9 \%)$ & 0.15 \\
\hline & Bring up any phlegm from the & No & $25(45.5 \%)$ & $6(46.2 \%)$ & $19(45.2 \%)$ & \\
\hline & $\begin{array}{c}\text { chest in the mornıng, durıng the } \\
\text { day or at night in the winter }\end{array}$ & Yes & $30(54.5 \%)$ & $7(53.8 \%)$ & $23(54.8 \%)$ & 1 \\
\hline
\end{tabular}

Table 2: Association between storage of dried tobacco leaves and respiratory diseases.

of self-reported allergies (nasal allergies and skin allergies or eczema) in this study are also lower than the findings by Waked and Salameh [22] where $21.1 \%$ had allergic rhinitis and $7.0 \%$ had atopic eczema at the Nabatieh Governate level. On the other hand, in South America (mainly in Southern Brazil), Fiori et al. reported wheezing prevalence of $11 \%$ among tobacco farm workers [23].

This is the first study that attempted at quantifying the effect of indoor house storage of dried tobacco leaves on respiratory symptoms in tobacco farm house-holds planting oriental tobacco leaves. Identifying exposure status and data in the farming community is a challenging task. Genetics, human behavior, farming activities, and frequency of exposure to the different farming asthmogens/irritants, other indoor environmental toxicants or irritants are likely to influence the development and/or aggravation of respiratory symptoms. The study reported a positive association between indoor tobacco leaves storage and exacerbation of respiratory symptoms, nevertheless, it did not reach statistical significance. Around $87 \%$ of the farmers suffering from a pre-existing respiratory illness (equivalent to $5 \%$ of the surveyed households) reported symptoms when working around in a room where dried tobacco leaves are stored.

The study by Hoppin et al. [24] also found little evidence of positive association between prevalence of asthma and concurrent farming activities. Chloros et al. study of 1,020 seasonal and permanent tobacco workers do not support an association between the development 


\begin{tabular}{|c|c|c|}
\hline Predictors & OR (95\% Cl) & P value \\
\hline Storage status of dried tobacco leaves & $1.68(0.93-3.03)$ & 0.09 \\
\hline $\begin{array}{c}\text { Variables entered in the model are: Storage status of dried tobacco leaves, Age, } \\
\text { Gender, Education level, Experience in tobacco farming, family size, annual } \\
\text { income, house size, indoor heating, indoor air conditioning, Storage period, } \\
\text { number of smokers }\end{array}$ \\
\hline
\end{tabular}

Table 3: Multivariate analysis for the predictors of any respiratory disease having the storage status of dried tobacco as main exposure.

of chronic diseases of the lower respiratory system and pollutants associated with the processing of dried tobacco leaves in a factory in Thessaloniki in Greece [25].

The findings of our study are partly explained by the common practice of household of opening windows during the day thereby minimizing indoor accumulation of dusts and particulates; and minimizing exposure to such indoor pollutants. Almost all open windows at least once per day for more than 4 hours to aerate the room where dried tobacco leaves are stored. The finding that a higher percent of those reporting respiratory symptoms store dried tobacco leaves outside their home can be explained by the reverse causality (i.e. those who are aware of their respiratory symptoms triggers are more likely to store it outside). Follow up phone interviews with around 10 participants in February 2013 further confirmed that dried tobacco leaves are stored outside occupied home premises (whenever alternative places are present/ or can be arranged) primarily to maintain house cleanliness; and, those who are aware of their respiratory and allergic diseases, store it outside to minimize the aggravation of their respiratory symptoms and allergies. Moreover, our findings are expected to be underestimated due to the healthy-worker effect, since our study included healthy and active tobacco farmers and excluded non-active farmers, with potential health problems. Close to two thirds $(60 \%)$ of participating farmers had more than 16 years of experience in tobacco farming versus $40 \%$ with less than 16 years of experience. Moreover, $32.6 \%$ were 40 years old or less which may have contributed to the healthy worker and healthy survivor effect. The long years of experience (as a proxy indicator of chronic exposure to dried tobacco leaves) among adults is likely to attenuate the observed hypothesized relationship in-between indoor storage of dried tobacco leaves and reporting of respiratory symptoms towards null hypothesis (or no association) [26-28]. It is possible that the persistent exposure to dried tobacco leaves inside the house might make it difficult to "detect" an association between exposure and the mild phase of the disease [26-28]. It is also possible that early life exposure in childhood to tobacco farming lifestyle might have a protective effect during immune maturation against asthma, hay fever and allergic sensitization through specific regulatory pathways $\mathrm{T}$ cells [29].

This study is not without limitations, where it is based on selfreported respiratory and allergic symptoms by study participants which can be less valid measure than physician diagnosed asthma corroborated with objective diagnostic test results. Nevertheless, we do not anticipate major effect of this point, as the self-report of asthma was verified against the prescribed medications at the time of the interview (data not shown) [30]. Another limitation is the small sample size, which might have affected the power of the study to detect statistical significance, as well as failure to include other potential confounders in multivariate analyses.

\section{Conclusion}

From a public health perspective, the indoor storage of dried tobacco leaves can be a risk factor for asthma severity or aggravation of respiratory symptoms in both adults and children. The low percent of reported respiratory symptoms can be explained by the limited storage period (91.3 days) inside home [15], healthy worker and healthy survivor effect, reverse causation, protective measures taken to store dried leaves outside occupied premises to maintain house cleanliness and minimize effect of dried leaves smell and dust on those with respiratory symptoms.

As risk factors for incidence of asthma can be different from risk factors for asthma severity, prospective cohort studies in tobacco farming communities would be useful in determining if indoor storage of dried tobacco leaves can lead to development of asthma and aggravation of symptoms especially among younger age group.

\section{Funding}

IDRC project number 104639-999070777-006

\section{Competing Interests}

The authors declare that they have no competing interests.

\section{References}

1. Mustajbegovic J, Zuskin E, Schachter EN, Kern J, Luburic-Milas M, et al. (2003) Respiratory findings in tobacco workers. Chest 123: 1740-1748.

2. Zhang Y, Chen J, Chen Y, Dong J, Wei Q, et al. (2005) Environmenta mycological study and allergic respiratory disease among tobacco processing workers. J Occup Health 47: 181-187.

3. Viegi G, Paggiaro PL, Begliomini E, Vaghetti E, Paoletti P, et al. (1986) Respiratory effects of occupational exposure to tobacco dust. Brit J Indus Med 43: 802-808.

4. Valic F, Beritic D, Butkovic D (1976) Respiratory response to tobacco dust exposure. Am Rev Respir Dis 113: 751-755.

5. Ignacak A, Guzik TJ, Gorski L, Czerniawska-Mysik G, Adamek-Guzik T (2002) Influence of tobacco dust on the respiratory system and selected immunological parameters. Przeglad lekarski 59: 789-792.

6. Mukhtar MS, Rao GM, Gamra NS, Afan AM, Zendah MI (1991) Respiratory effects of occupational exposure to tobacco dust. Respiration 58: 271-276.

7. Mengesha YA, Bekele A (1998) Relative chronic effects of different occupational dusts on respiratory indices and health of workers in three Ethiopian factories. Am J Indus Med 34: 373-380.

8. Huuskonen MS, Husman K, Jarvisalo J, Korhonen O, Kotimaa M, et al. (1984) Extrinsic allergic alveolitis in the tobacco industry. $\mathrm{Br} \mathrm{J}$ Ind Med 41:77-83.

9. Bhisey RA, Bagwe AN, Mahimkar MB, Buch SC (1999) Biological monitoring of bidi industry workers occupationally exposed to tobacco. Toxicol Lett 108 : 259-265.

10. Gleich GJ, Welsh PW, Yunginger JW, Hyatt RE, Catlett JB (1980) Allergy to tobacco: An occupational hazard. The New Eng J Med 302: 617-619.

11. Ghosh SK, Parikh JR, Gokani VN, Rao NM, Doctor PB (1985) Occupationa health problems among tobacco processing workers: A preliminary study. Arch Environment Health 40: 318-321.

12. Riquinho DL, Hennington EA (2012) Health, environment and working conditions in tobacco cultivation: A review of the literature. Cien Saude Colet 17: $1587-1600$.

13. Lecours N, Almeida GE, Abdallah JM, Novotny TE (2012) Environmental health impacts of tobacco farming: A review of the literature. Tobacco control 21: 191 196.

14. Gumus SG (2008) Economic analysis of oriental tobacco in turkey. Bulgarian J Agri Sci 14: 470-475

15. Bazzi A, Darwish MR, Israwi F, Kabbani N (2008) Raw tobacco price subsidy: Implications for farm income and natural productive resources.

16. Srour AZ (2002) The role of reggee (The lebanese tobacco and tombac company) in tobacco cultivation in lebanon: Between the present and the past.

17. Arcury TA, Quandt SA (1998) Chronic agricultural chemical exposure among migrant and seasonal farmworks. Society Nat Res 11: 829-843. 
Citation: Bazzi A, Zaatari G, Makki M, Tamim H, Zein-El-Dine S (2018) Relation of Indoor Storage of Dried Tobacco Leaves to Reporting of Respiratory Symptoms: Case of Tobacco Farms Households in South Lebanon. J Pulm Respir Med 8: 478. doi: 10.4172/2161-105X.1000478

Page 7 of 7

18. Thompson B, Coronado GD, Grossman JE, Puschel K, Solomon CC, et al. (2003) Pesticide take-home pathway among children of agricultural workers: Study design, methods, and baseline findings. J Occup Environment Med 45: 42-53.

19. Quandt SA, Hernandez-Valero MA, Grzywacz JG, Hovey JD, Gonzales M, et al. (2006) Workplace, household, and personal predictors of pesticide exposure for farmworkers. Environment Health Perspect 114: 943-952.

20. Rao P, Gentry AL, Quandt SA, Davis SW, Snively BM, et al. (2006) Pesticide safety behaviors in Latino farmworker family households. Am J Indus Med 49: $271-280$

21. Janson C, Anto J, Burney P, Chinn S, de Marco R, et al. (2001) The European community respiratory health survey: What are the main results so far? European community respiratory health survey II. The Euro Resp J 18: 598611.

22. Waked M, Salameh $P$ (2008) Risk factors for asthma and allergic diseases in school children across Lebanon. J Asthma allergy 2: 1-7.

23. Fiori NS, Fassa AG, Faria NM, Meucci RD, Miranda VI, et al. (2015) Wheezing in tobacco farm workers in southern Brazil. Am J Indus Med 58: 1217-1228.

24. Hoppin JA, Umbach DM, London SJ, Henneberger PK, Kullman GJ, et al.
(2009) Pesticide use and adult-onset asthma among male farmers in the agricultural health study. The Euro Resp J 34: 1296-1303.

25. Chloros D, Sichletidis L, Kyriazis G, Vlachogianni E, Kottakis I, et al. (2004) Respiratory effects in workers processing dried tobacco leaves. Allergo Immunopathol 32: 344-351.

26. Le Moual N, Siroux V, Pin I, Kauffmann F, Kennedy SM et al. (2005) Asthma severity and exposure to occupational asthmogens. Am J Respir Crit Care Med 172: 440-445.

27. Malo JL (2005) Asthma may be more severe if it is work-related. Am J Respir Crit Care Med 172: 406-407.

28. Le Moual N, Varraso R, Zock JP, Henneberger P, Speizer FE, et al. (2013) Are operating room nurses at higher risk of severe persistent asthma? the nurses' health study. J Occup Environ Med 55: 973-977.

29. Lluis A, Depner M, Gaugler B, Saas P, Casaca VI, et al. (2014) Increased regulatory $\mathrm{T}$-cell numbers are associated with farm milk exposure and lower atopic sensitization and asthma in childhood. J Allergy Clin Immunol 133: 551559 .

30. Furu K, Karlstad O, Skurtveit S, Haberg SE, Nafstad P, et al. (2011) High validity of mother-reported use of antiasthmatics among children: A comparison with a population-based prescription database. J Clin Epidemiol 64: 878-884. 